\title{
ASPECTOS CLÍNICOS E GENÉTICOS NO DIAGNÓSTICO PRECOCE DA SÍNDROME DE WILLIAMS-BEUREN: EVIDÊNCIAS ATUAIS
}

\author{
CLINICAL AND GENETIC ASPECTS IN THE EARLY DIAGNOSIS \\ OF WILLIAMS-BEUREN SYNDROME: CURRENT EVIDENCE \\ ASPECTOS CLÍNICOS Y GENÉTICOS EN EL DIAGNÓSTICO PRECOZ \\ DEL SÍNDROME DE WILLIAMS-BEUREN: PRUEBAS ACTUALES
}

\author{
Fabyanne França de Santana ${ }^{1}$ \\ Karolline de Albuquerque Oliveira ${ }^{2}$ \\ Uirassú Tupinambá Silva de Lima ${ }^{3}$
}

\begin{abstract}
RESUMO: INTRODUÇÃO: as crianças fragilizadas por esta síndrome apresentam um conjunto de sinais e sintomas característicos, os quais variam de acordo com a extensão do dano nos genes responsáveis pela patologia. Considerando a carência de pesquisas e de literatura no Brasil no tocante a este agravo na saúde da criança, resolveu-se pelo desenvolvimento desta temática como trabalho de conclusão de curso de enfermagem. OBJETIVO: identificar na literatura atual aspectos clínicos e genéticos envolvidos no diagnóstico médico precoce da síndrome de Williams-Beuren. METODOLOGIA: consistiu em um estudo de revisão integrativa de literatura, através de pesquisa nas bases de dados Literatura Latino-Americana e do Caribe Ciências da Saúde (LILACS), Medical Literatura Análise e Retrieval System on-line (MEDLINE), Public Medline (PubMed) e as bibliotecas virtuais Scientific Electronic Library Online (SciELO), essas escolhidas por sua larga difusão acadêmica. RESULTADOS E DISCUSSÃO: evidenciou-se ser necessário que os profissionais da saúde, em especial os enfermeiros, de todos os níveis assistenciais, possuam competências e habilidades generalistas relacionadas a essa patologia, que englobem além dos conhecimentos fenotípicos e aspectos clínicos, que possam direcionar de maneira rápida, efetiva e segura seus processos de trabalho. CONSIDERAÇÕES FINAIS: o enfermeiro frente a essa condição clínica, precisa compreender a rede de desdobramento dos sinais e sintomas envolvidos, para que em seguida possa alinhar o Processo de Enfermagem (PE) para uma assistência mais qualitativa, autônoma, humana e interprofissional.
\end{abstract}

Descritores: Síndrome de Williams - Beuren; Diagnóstico; Aspectos Clínicos.

ABSTRACT: INTRODUCTION: children made fragile by this syndrome present a set of characteristic signs and symptoms, which vary according to the extension of the damage in the genes responsible for the pathology. Considering the lack of research and literature in Brazil regarding this grievance in children's health, we decided to develop this theme as the final paper of the nursing course. OBJECTIVE: identify clinical and genetic aspects involved in early medical diagnosis of Williams-Beuren syndrome in the current literature. METHODOLOGY: this was an integrative literature review study, by searching the databases Latin American and Caribbean Health Sciences Literature (LILACS), Medical Literature Analysis and Retrieval System on-line (MEDLINE), Public Medline (PubMed) and the virtual libraries Sci-entific Electronic Library Online (SciELO), chosen for their wide academic diffusion. RESULTS AND DISCUSSION: it was

\footnotetext{
I Graduanda do Curso de Bacharelado em Enfermagem do Centro Universitário Cesmac. E-mail: fabyannefranca@gmail.com.

${ }^{2}$ Graduanda do Curso de Bacharelado em Enfermagem do Centro Universitário Cesmac. E-mail: karollinemcz@gmail.com.

3 Professor titular do Centro Universitário Cesmac. E-mail: uirassu.lima@cesmac.edu.br.
} 
evidenced that it is necessary that healthcare professionals, especially nurses, from all levels of care, have generic competences and skills related to this pathology, which include not only phenotypic knowledge and clinical aspects, but also the ability to quickly, effectively and safely guide their work processes. FINAL CONSIDERATIONS: the nurse facing this clinical condition, needs to understand the unfolding network of signs and symptoms involved, so that then can align the Nursing Process (NP) for a more qualitative, autonomous, human and interprofessional assistance.

Descriptors: Williams - Beuren Syndrome; Diagnosis; Clinical Aspects.

RESUMEN: INTRODUCCIÓN: los niños fragilizados por este síndrome presentan un conjunto de signos y síntomas característicos, que varían según la extensión del daño en los genes responsables de la patología. Considerando la falta de investigación y literatura en Brasil sobre este agravio en la salud infantil, decidimos desarrollar este tema como trabajo final del curso de enfermería. OBJETIVO: identificar en la literatura actual los aspectos clínicos y genéticos implicados en el diagnóstico médico precoz del síndrome de Williams-Beuren. METODOLOGÍA: se trata de un estudio de revisión bibliográfica integradora, mediante la búsqueda en las bases de datos Latin American and Caribbean Health Sciences Literature (LILACS), Medical Literature Analysis and Retrieval System on-line (MEDLINE), Public Medline (PubMed) y en las bibliotecas virtuales Scientific Electronic Library Online (SciELO), elegidas por su amplia difusión académica. RESULTADOS Y DISCUSIÓN: se evidenció que los profesionales de la salud, especialmente los de enfermería, en todos los niveles de atención, deben tener competencias y habilidades genéricas relacionadas con esta patología, que incluyen no sólo el conocimiento fenotípico y los aspectos clínicos, sino también la capacidad de orientar de manera rápida, efectiva y segura sus procesos de trabajo. CONSIDERACIONES FINALES: la enfermera que se enfrenta a esta condición clínica necesita entender el despliegue de la red de signos y síntomas implicados, para luego poder alinear el Proceso de Enfermería (PN) para una asistencia más cualitativa, autónoma, humana e interprofesional.

Descriptores: Síndrome de Williams - Beuren; Diagnóstico; Aspectos clínicos.

\section{INTRODUÇÃO}

O objeto de estudo desta pesquisa compreende os aspectos clínicos e genéticos da Síndrome de Willams-Beuren (SWB). O interesse por essa temática se deu pela necessidade de se explorar a respeito dessa doença pouco abordada, a fim de gerar informações e conhecimentos, os quais possam contribuir para os profissionais da saúde no manejo da doença e diagnóstico precoce. E no caso, particular da enfermagem, para o delineamento dos focos e julgamentos pertinentes ao Processo de Enfermagem (PE). Para abordar a temática se fez necessário conhecer um marco teórico inicial da doença.

A SWB foi descrita pelo médico neozelandês John Williams em 1961 e 1962 por Adam Beuren na Alemanha, onde pôde-se observar um conjunto de sinais e sintomas semelhantes e comuns em alguns pacientes pediátricos, como: problemas cardiovasculares, atraso mental, rostos com características semelhantes, ocasionando à atenção para as peculiaridades da síndrome (AMARAL, et al. 2014).

Nesses pacientes ocorre a deleção, que é a perda de uma das cópias dos genes, situados na região 7qII.23, onde a mesma acontece em cinco a cada Io mil recém-nascidos (MATTOS, et al. 2017). Podendo haver a deleção de 20 a 28 genes na região desse cromossomo (VIDAL, et al. 2012; MATTOS, et al. 2017).

As crianças afetadas pela síndrome apresentam um conjunto de sintomas e características clínicas, as quais variam de acordo com a extensão do dano nos genes responsáveis pela patologia (GRAZIANIA, et al. 2017). Uma das características marcantes estão as de 
cunho faciais, que são bem típicas, como o nariz em sela, discreto inchaço em volta das pálpebras, bochechas cheias, lábios grossos, sorriso largo, sulco nasolabial longo (MATTOS, et al. 2017; AMARAL, et al. 2013).

Porém a busca pelo diagnóstico, bem como a presença dele em toda etapa, é muito importante, visto que em muitas situações os mesmos passam por um processo longo de procura, dificuldades e adversidades, uma caminhada difícil para obter uma resposta confirmatória (SANTOS, et al. 2013).

Partindo da hipótese que o diagnóstico precoce é de crucial importância para a relação da família com a criança sindrômica e seu convívio em sociedade. O conhecimento acerca dos aspectos clínicos e genéticos contribuem significativamente para o diagnóstico prévio e a assistência de forma holística, multiprofissional, interprofissional e direcionada para conceder suporte para o paciente e sua família no manejo da doença.

Com isso, essa revisão se justifica diante da necessidade da ampliação de pesquisas acerca da SWB, afim de produzir conhecimento científico baseado em evidências, oportunizando fundamentação teórica para o processo de trabalho da equipe de saúde, em especial para enfermagem assistencial. Diante do exposto, a questão disparadora aqui proposta foi: quais são as caraterísticas clínicas e genéticas no diagnóstico precoce da Síndrome de Williams-Beuren constante na literatura científica atual?

E o objetivo geral, proposto, foi identificar na literatura atual aspectos clínicos e genéticos envolvidos no diagnóstico médico precoce da SWB.

\section{METODOLOGIA}

Trata-se de um estudo descritivo de revisão integrativa da literatura, que segundo Olga et. al (2016), tem por finalidade "reunir e sintetizar achados de estudos realizados, mediante diferentes metodologias, com o intuito de contribuir para o aprofundamento do conhecimento relativo ao tema investigado". Contribuindo para o cuidado em saúde, sobretudo para a enfermagem, à medida que se torna capaz de integrar o conhecimento produzido em diversas disciplinas, compreendendo este mesmo cuidado como integral (RIBEIRO, MARTINS, TRONCHIN, 20I6).

O estudo foi realizado conforme rigor metodológico nas seguintes etapas: formulação da questão para a elaboração da revisão integrativa da literatura; especificação dos métodos de seleção dos estudos; procedimento de extração dos dados; análise e avaliação dos estudos incluídos na revisão integrativa da literatura; extração dos dados e apresentação da revisão/síntese do conhecimento produzido e publicado.

$\mathrm{O}$ método adotado permite a síntese dos resultados de pesquisas relevantes e reconhecidas, que facilita e acelera a incorporação de evidências, novas descobertas na pratica clínica, de pesquisa, educação e administração. Possibilitando, ao profissional, fundamentação para condutas e tomadas de decisões a partir de um saber crítico.

Para contextualização do estudo será realizada revisão de literatura do tipo bibliográfica no banco de dados on-line: Literatura Latino-Americana e do Caribe Ciências da Saúde (LILACS), Medical Literatura Análise e Retrieval System on-line (MEDLINE), Public Medline (PubMed) e as bibliotecas virtuais Scientific Electronic Library Online (SciELO). Para a seleção dos artigos, serão utilizados os descritores contemplados nos Descritores em Ciências da Saúde (DeCS), como: aspectos clínicos; diagnóstico; Sindrome 
de Williams.

Os critérios de inclusão utilizados foram: artigos publicados de 2013 a 2021, nos idiomas português e inglês, disponíveis gratuitamente e na íntegra em texto completo nas bases de dados pré-estabelecidas. Já os critérios de exclusão foram: artigos indisponíveis na íntegra, que não respondiam à questão desta pesquisa, repetidos na mesma ou em mais de uma fonte de dados e estudos de revisão/análise.

A fase da avaliação foi realizada a partir da análise crítica dos dados obtidos, avaliando critérios de autenticidade, qualidade metodológica e importância das informações.

A revisão integrativa foi apresentada contendo detalhes explícitos das pesquisas a fim de conceder ao leitor condições de analisar a conformidade dos procedimentos realizados. Os resultados serão apresentados na forma de tabela, sendo as informações apresentadas em dois seguimentos, um relacionado às características de identificação do artigo (base de dados, revista, ano de publicação, autor (es), título, idioma e tipo de publicação) e outro relacionado às características metodológicas do estudo (tipo de estudo, objetivo, amostra, tamanho da amostra, fatores, conclusão).

O cruzamento será realizado utilizando os operadores booleanos AND, sendo cruzados os descritores entre si, até alcançar uma quantidade de artigos para compor a amostra de forma satisfatória.

Para os resultados foram realizadas as etapas de identificação dos artigos que respondessem a questão norteadora, analisadas através de um instrumento adaptado, contendo o título do artigo, autores, ano de publicação, objetivo da pesquisa, metodologia utilizada e resultados da pesquisa.

Tabela I - Distribuição da quantidade de publicações obtidas nas bases de dados LILACS, SciELO e MEDLINE de acordo com os descritores selecionados, Maceió, 202I.

\begin{tabular}{|c|c|c|c|c|c|c|c|}
\hline ESTRATÉGIA DE BUSCA* & \multicolumn{2}{|c|}{ LILACS } & \multicolumn{2}{|c|}{ SCIELO } & \multicolumn{2}{|c|}{$\begin{array}{l}\text { MEDLIN } \\
\mathrm{E}\end{array}$} & \multirow[t]{2}{*}{ TOTAL } \\
\hline & $\mathrm{E}$ & $\mathrm{S}$ & $\mathrm{E}$ & $\mathrm{S}$ & E & $\mathrm{S}$ & \\
\hline $\begin{array}{l}\text { "Aspectos Clínicos" AND "Síndrome de Willi- } \\
\text { ams-Beuren" }\end{array}$ & 3 & I & 3 & o & 2 & I & 2 \\
\hline $\begin{array}{l}\text { "Síndrome de Williams-Beuren" AND “Di- } \\
\text { agnóstico" }\end{array}$ & 42 & 3 & 12 & I & 27 & o & 4 \\
\hline $\begin{array}{l}\text { "Síndrome de Williams-Beuren" AND “Diagnós- } \\
\text { tico" AND "Aspectos Clínicos" }\end{array}$ & 5 & o & 8 & $\mathrm{I}$ & 2 & o & $\mathrm{I}$ \\
\hline Total & & & & & & & 8 \\
\hline
\end{tabular}

*A pesquisa foi realizada com os descritores na língua portuguesa, utilizando os operadores booleanos AND.

*Os artigos encontrados repetidamente nas bases de dados foram excluídos.

Legenda: E- encontrado; S- selecionado.

\section{RESULTADOS E DISCUSSÃO}

Foram selecionados 8 artigos que atenderam aos critérios de inclusão previamente estabelecidos. Do total das amostras selecionadas, 6 artigos são produções brasileiras e dois internacionais. Quanto ao local de desenvolvimento dos estudos no Brasil, a região Sudeste 
encontra-se como a maior contribuinte da produção científica encontrada, seguida da região Nordeste. A região Centro-Oeste e a região Sul apresentam um artigo cada.

Dentre os resultados encontrados as revistas que tiveram publicações foram: Cad. Ter. Ocup. UFSCar; Psicol. pesq ; Rev. Health Qual Life Outcomes; R. Bioeducação; Revista Destaques Acadêmicos; Psicol. esc. Educ; Brazilian Journal of Health Review; CESPUC.

Os achados descritos nos artigos tiveram aspectos importantes a serem avaliados na seguinte revisão, foram descritos abaixo, autor, tema e periódico (Tabela I).

Quadro I. Artigos científicos selecionados nas bases de dados LILACS, SCIELO e MEDLINE segundo o título, periódico e ano. Maceió, 2021.

\begin{tabular}{|c|c|c|}
\hline AUTORES & ARTIGO & PERIÓDICO \\
\hline AI & $\begin{array}{l}\text { Avaliação da influência dos sintomas clínicos na } \\
\text { qualidade de vida de indivíduos com Síndrome de } \\
\text { Williams-Beuren. }\end{array}$ & $\begin{array}{l}\text { Caderno Terapia Ocupacional. } \\
\text { UFSCar (Impr.) / } 2017 .\end{array}$ \\
\hline $\mathrm{A}_{2}$ & $\begin{array}{l}\text { Investigação dos domínios cognitivos de pacientes } \\
\text { com Síndrome de Williams usando as Escalas } \\
\text { Wechsler. }\end{array}$ & Psicologia pesquisa / 2014 . \\
\hline $\mathrm{A}_{3}$ & $\begin{array}{l}\text { Avaliação da qualidade de vida em famílias com } \\
\text { pacientes com Síndrome de Williams. }\end{array}$ & $\begin{array}{l}\text { Rev. Health Qual Life Out- } \\
\text { comes / 2021. }\end{array}$ \\
\hline \multicolumn{3}{|l|}{$\mathrm{A}_{4}$} \\
\hline & Sindrome de Williams-Beuren: artigo de revisão. & Revista Bioeducação/ 2014 \\
\hline A5 & $\begin{array}{l}\text { Cuidado de enfermagem na atenção primária à cri- } \\
\text { ança com Síndrome de Williams-Beuren: uma revi- } \\
\text { são integrativa. }\end{array}$ & $\begin{array}{l}\text { Revista Destaques Acadêmicos/ } \\
\text { 2020. }\end{array}$ \\
\hline A6 & $\begin{array}{l}\text { Estresse em crianças e adolescentes com Síndrome } \\
\text { de Williams-Beuren em idade escolar. }\end{array}$ & Psicologia escolar e educação/ 2014 \\
\hline $\mathrm{A}_{7}$ & $\begin{array}{l}\text { Correlações entre o fenótipo na Síndrome de Willi- } \\
\text { ams e os genes deletados. }\end{array}$ & $\begin{array}{c}\text { Brazilian Journal of Health Re- } \\
\text { view / 2021. }\end{array}$ \\
\hline A8 & $\begin{array}{l}\text { A aquisição da linguagem por parte de crianças com } \\
\text { Síndrome de Williams: um estudo de caso sobre a } \\
\text { compreensão de sentenças passivas. }\end{array}$ & $\begin{array}{l}\text { Cadernos CESPUC De Pesquisa } \\
\text { Série Ensaios / } 2018 .\end{array}$ \\
\hline
\end{tabular}

Fonte: Dados da revisão integrativa, Maceió, AL, 2021.

Após analisados os títulos dos artigos e os que haviam relação ao tema proposto, sendo feita a leitura dos resumos, foram identificados focos norteadores para o objetivo proposto, sendo 8 selecionados por terem correspondido à temática do estudo bibliográfico, através da amostra previamente estabelecida. 
Quadro 2: Avaliação e análise das informações especificas dos artigos selecionados. Resumo dos objetivos, resultados e conclusão. Maceió, 2021.

\begin{tabular}{|c|c|c|c|}
\hline Art & OBJETIVOS & RESULTADOS & CONCLUSÕES \\
\hline AI & $\begin{array}{l}\text { Este estudo teve como ob- } \\
\text { jetivo identificar possí- } \\
\text { veis sintomas clínicos nos } \\
\text { indivíduos com SWB e as } \\
\text { possíveis consequências } \\
\text { na qualidade de vida. }\end{array}$ & $\begin{array}{l}\text { Os resultados sugerem que os ado- } \\
\text { lescentes com SWB possuem uma } \\
\text { boa qualidade de vida, apesar de a- } \\
\text { presentarem maiores possibilida- } \\
\text { des de sintomas psiquiátricos. Es- } \\
\text { tes resultados são válidos, já que } \\
\text { a qualidade de vida é mensurada a } \\
\text { partir da subjetividade do indiví- } \\
\text { duo avaliado. }\end{array}$ & $\begin{array}{l}\text { Chega-se à hipótese de que os a- } \\
\text { dolescentes com SWB podem a- } \\
\text { presentar uma distorção da reali- } \\
\text { dade para o fator positivo/oti- } \\
\text { mista, possivelmente baseada em } \\
\text { algumas características da pró- } \\
\text { pria síndrome, tais como são } \\
\text { sempre alegres e sorridentes, fa- } \\
\text { tores associados à deficiência in- } \\
\text { telectual. }\end{array}$ \\
\hline $\mathrm{A}_{2}$ & $\begin{array}{l}\text { Analisar o perfil cognitivo } \\
\text { de uma série de ca- } \\
\text { sos de pacientes com } \\
\text { SWB, utilizando a Escala } \\
\text { Wechsler de Inteligência. }\end{array}$ & $\begin{array}{l}\text { Os resultados apontam para um pa- } \\
\text { drão de desempenho semelhante } \\
\text { entre os participantes na escala ver- } \\
\text { bal, porém o QI de execução teve } \\
\text { maior correlação com o QI total. }\end{array}$ & $\begin{array}{l}\text { Foi observada uma discrepância } \\
\text { entre habilidades verbais e não } \\
\text { verbais em } 40 \% \text { dos participantes. }\end{array}$ \\
\hline$A_{3}$ & $\begin{array}{l}\text { Conhecer o nível de } \\
\text { qualidade de vida descrito } \\
\text { por famílias com } \\
\text { Síndrome de Williams. }\end{array}$ & $\begin{array}{l}\text { A Síndrome de Williams é um } \\
\text { transtorno do desenvolvimento } \\
\text { caracterizado por uma deficiência } \\
\text { intelectual variável. Pessoas com } \\
\text { Síndrome de Williams precisam da } \\
\text { intervenção de vários especialistas } \\
\text { clínicos e educacionais ao longo de } \\
\text { sua vida. }\end{array}$ & $\begin{array}{l}\text { O impacto produzido por essa } \\
\text { deficiência em seu ambiente } \\
\text { imediato, especialmente nas } \\
\text { famílias. }\end{array}$ \\
\hline $\mathrm{A}_{4}$ & $\begin{array}{l}\text { Conhecer as principais ca- } \\
\text { racterísticas ocasionam a } \\
\text { Síndrome de Willians. }\end{array}$ & $\begin{array}{l}\text { Neste estudo foram examinados } \\
\text { artigos publicados no período entre } \\
2000 \text { e } 2011 \text {. Foram selecionados } 43 \\
\text { artigos, dos quais } 34 \text { foram usados } \\
\text { como base para esta revisão. Crité- } \\
\text { rios de exclusão: Os artigos excluí- } \\
\text { dos não tinham como tema central } \\
\text { a SWB ou não traziam atualização } \\
\text { relevante sobre o tema. Critérios de } \\
\text { inclusão: Artigos e teses que tives- } \\
\text { sem como tema central a SWB, a- } \\
\text { bordando os mais diversos aspectos } \\
\text { da patologia. A coleta de dados o- } \\
\text { correu entre janeiro e abril zorr. As } \\
\text { alterações físicas mais comuns são } \\
\text { as cardiovasculares (estenose aór- } \\
\text { tica supravalvular e pulmonar peri- } \\
\text { férica), fácies característica, atraso } \\
\text { de crescimento, além das alterações } \\
\text { comportamentais e atraso mental } \\
\text { que, pelas suas peculiaridades, mo- } \\
\text { tivam especial atenção. Não se co- } \\
\text { nhecem as interações gene-gene ou } \\
\text { gene-ambiente. O diagnóstico é clí- } \\
\text { nico, tendo como exame padrão- } \\
\text { ouro o teste de Fish. É necessário o }\end{array}$ & $\begin{array}{l}\text { Conclui-se que a SWB necessita } \\
\text { ser mais conhecida e diagnosti- } \\
\text { cada pelos médicos, em especial } \\
\text { pelos pediatras, para fins terapêu- } \\
\text { ticos e de manejo adequado do pa- } \\
\text { ciente portador. }\end{array}$ \\
\hline
\end{tabular}




\begin{tabular}{|c|c|c|c|}
\hline & & $\begin{array}{l}\text { encaminhamento desses pacientes } \\
\text { para equipes multiprofissionais. }\end{array}$ & \\
\hline As & $\begin{array}{l}\text { O presente estudo foi o de } \\
\text { produzir e avaliar um ví- } \\
\text { deo informativo e de ori- } \\
\text { entação direcionado a pais } \\
\text { e cuidadores sobre o ma- } \\
\text { nejo comportamental de } \\
\text { pessoas com Síndrome de } \\
\text { Williams-Beuren. }\end{array}$ & $\begin{array}{l}\text { A revisão (pesquisa) bibliográfica } \\
\text { permitiu a posse de informações } \\
\text { sobre a SWB que constam nos tra- } \\
\text { balhos realizados por pesquisado- } \\
\text { res relacionados em nosso Referen- } \\
\text { cial Teórico. A Síndrome é rara e } \\
\text { está associada a fenótipos neuro- } \\
\text { cognitivos e comportamentais que } \\
\text { devem ser entendidos como a base } \\
\text { para a pesquisa de padrões compor- } \\
\text { tamentais, emocionais e cogniti- } \\
\text { vos, sem desconsiderar a influência } \\
\text { do ambiente e sua ligação com o dé- } \\
\text { ficit intelectual. Através do conhe- } \\
\text { cimento dos sintomas, é possível a- } \\
\text { judar no diagnóstico precoce, pro- } \\
\text { porcionando melhor manejo com o } \\
\text { indivíduo e melhora na qualidade } \\
\text { de vida. Para contribuir, desenvol- } \\
\text { vemos e produzimos um vídeo re- } \\
\text { portagem de orientação para } \\
\text { pais/cuidadores, tendo como ob- } \\
\text { jeto central a disseminação de in- } \\
\text { formações e cuidados com indiví- } \\
\text { duos com a Síndrome de Williams- } \\
\text { Beuren. }\end{array}$ & $\begin{array}{l}\text { Concluindo, pode-se ponderar } \\
\text { que o vídeo produzido e avaliado } \\
\text { na presente tese apresenta rele- } \\
\text { vantes orientações através da } \\
\text { forma televisiva, e atende às ne- } \\
\text { cessidades informativas do pú- } \\
\text { blico alvo, com uma proposta de } \\
\text { fácil acesso. Entendemos que } \\
\text { com esta produção, podemos con- } \\
\text { tribuir de forma marcante com o } \\
\text { desenvolvimento social e infor- } \\
\text { mativo a pais e cuidadores. }\end{array}$ \\
\hline A6 & $\begin{array}{l}\text { Objetivamos conhecer cri- } \\
\text { anças e adolescen- } \\
\text { tes com síndrome de Wil- } \\
\text { liams-Beuren apresentam } \\
\text { níveis elevados de es- } \\
\text { tresse. Avaliamos } 40 \text { indi- } \\
\text { víduos em idade escolar, } \\
\text { com diagnóstico } \\
\text { da Síndrome de Williams- } \\
\text { Beuren e grupo controle. }\end{array}$ & $\begin{array}{l}\text { Os instrumentos utilizados escala } \\
\text { de Estresse Infantil (ESI), Escala } \\
\text { de Inteligência para Crian- } \\
\text { ças (WISC), Escala de Inteligên- } \\
\text { cia para Adultos (WAIS) } \\
\text { um questionário semiestruturado. } \\
\text { No grupo com o SWB, 50\% tinham } \\
\text { altos níveis de estresse em compa- } \\
\text { ração com 28,6\% no grupo controle, } \\
\text { diferença altamente significativa } \\
\text { estatisticamente (p <o,ooI). De es- } \\
\text { cola de inclusão, 40,7\% apresenta- } \\
\text { ram maior estresse; de escola espe- } \\
\text { cial, 69,2\% (p> o,I40). Indivíduos } \\
\text { com Síndrome de Williams mos- } \\
\text { tram índice elevado de estresse. }\end{array}$ & $\begin{array}{l}\text { Este estudo destaca a necessidade } \\
\text { de orientação sobre a sín- } \\
\text { drome a pais e gestão escolar, } \\
\text { com foco na redução de possíveis } \\
\text { fatores ambientais estressantes. }\end{array}$ \\
\hline$\overline{A_{7}}$ & $\begin{array}{l}\text { Realizar uma pesquisa bi- } \\
\text { bliográfica acerca da Sin- } \\
\text { drome de Williams-Beu- } \\
\text { ren e levantar estudos } \\
\text { mostrando o desenvolvi- } \\
\text { mento musical e social dos } \\
\text { portadores. }\end{array}$ & $\begin{array}{l}\text { A Síndrome de Willians é causada } \\
\text { pela perda de um ou mais genes do } \\
\text { braço longo do cromossomo } 7 \text {, ao } \\
\text { que se dá o nome de síndrome dos } \\
\text { genes contíguos (Figura } 1 \text { ). Nessa } \\
\text { região existem dois genes impor- } \\
\text { tantes para o aparecimento dos a- } \\
\text { chados listados pelos médicos pio- } \\
\text { neiros no relato da síndrome: o da }\end{array}$ & $\begin{array}{l}\text { Quanto mais precocemente for } \\
\text { diagnosticada melhor será o de- } \\
\text { sempenho neuropsicomotor da } \\
\text { criança. Esses achados poderão } \\
\text { ainda auxiliar na compreensão de } \\
\text { mecanismos relacionados à per- } \\
\text { sonalidade, cognição e linguagem } \\
\text { sob uma perspectiva genética, } \\
\text { não somente de sujeitos com a }\end{array}$ \\
\hline
\end{tabular}




\begin{tabular}{|c|c|c|c|}
\hline & & $\begin{array}{l}\text { elastina (ELN) - aparentemente } \\
\text { responsável pelos defeitos cardía- } \\
\text { cos - e o LiMquinase, que está as- } \\
\text { sociado à noção de visão espacial. }\end{array}$ & $\begin{array}{l}\text { SWB, mas da humanidade de } \\
\text { uma forma geral. }\end{array}$ \\
\hline A8 & $\begin{array}{l}\text { Apresenta o resultado de } \\
\text { um estudo de caso que teve } \\
\text { como foco a verificação da } \\
\text { compreensão de sentenças } \\
\text { passivas por parte de uma } \\
\text { criança com a Síndrome } \\
\text { de Williams, uma rara do- } \\
\text { ença genética que revela, } \\
\text { nas pessoas com essa con- } \\
\text { dição, um perfil cognitivo, } \\
\text { comportamental e comu- } \\
\text { nicativo bastante peculiar. }\end{array}$ & $\begin{array}{l}\text { Os resultados obtidos revelam um } \\
\text { desempenho significativamente } \\
\text { inferior da criança SW na compre- } \\
\text { ensão de sentenças passivas longas } \\
\text { quando comparadas ao grupo con- } \\
\text { trole, o que sugere que a sintaxe na- } \\
\text { quele sujeito não esteja intacta. }\end{array}$ & $\begin{array}{l}\text { Os resultados dos testes do es- } \\
\text { tudo ora reportado revelam um } \\
\text { desempenho na compreensão de } \\
\text { sentenças passivas da criança } \\
\text { SW consideravelmente inferior } \\
\text { ao do grupo controle, formado } \\
\text { por crianças típicas, sobretudo } \\
\text { em sentenças passivas longas, nas } \\
\text { quais há a presença de um by- } \\
\text { phrase explícito e foneticamente } \\
\text { realizado. }\end{array}$ \\
\hline
\end{tabular}

Fonte: Dados da revisão integrativa, Maceió, AL, 2021.

Relacionado ao ano de publicação de mais predomínio dos estudos selecionados, foram os anos de 2014 e 2021 com 2 artigos cada, sendo sucedido pelos anos de 2013, 2017, 2018 e 2020 que tiveram apenas 4 artigos no total.

Quadro 3. Distribuição da quantidade e percentagem dos artigos selecionados, indexados nas bases de dados LILACS, MEDLINE e SCIELO, no período 2013 a 2021, segundo o ano de publicação. Maceió, 2021.

\begin{tabular}{|c|c|c|}
\hline Ano de Publicação & Quantidade de Artigos & $\%$ \\
\hline 2021 & 02 & $25 \%$ \\
\hline 2020 & - & - \\
\hline 2019 & - & $12,5 \%$ \\
\hline 2018 & or & $12,5 \%$ \\
\hline 2017 & or & - \\
\hline 2016 & - & $12,5 \%$ \\
\hline 2015 & o1 & $25 \%$ \\
\hline 2014 & 02 & $12,5 \%$ \\
\hline 2013 & or & $100 \%$ \\
\hline TOTAL & 08 & - \\
\hline
\end{tabular}

Fonte: Dados da revisão integrativa, Maceió, AL, 2021.

Os artigos foram especificados quanto ao modelo de sistematização de estudo, sendo assim distribuídos em: 4 estudos qualitativos com abordagem descritiva; 3 estudos quantitativo e I Estudo sistemático (Tabela 4 ). 
Quadro 4. Distribuição dos artigos selecionados, indexados nas bases de dados, LILACS, SCIELO e MEDLINE, segundo tipo de estudo. Maceió, 202I.

\begin{tabular}{lcc}
\hline \multicolumn{1}{c}{ Tipo de estudo } & $\mathrm{N}$ & $\%$ \\
\hline Estudo qualitativo & 4 & $50 \%$ \\
& & \\
Estudo quantitativo & 3 & $37,5 \%$ \\
Estudo sistemático & & \\
\hline
\end{tabular}

Fonte: Dados da revisão integrativa, Maceió, AL, 2021.

A SWB é uma doença relativamente rara, pouco conhecida popularmente por sua baixa incidência na população geral, porém vem despertando cada vez mais as necessidades de pesquisas mais especificas, acerca das possíveis causas dessa variabilidade (GRAZIANIA, et al. 20I7). Estima-se que a cada Io.ooo mil crianças nascidas vivas, apenas cinco apresentam a Síndrome de Williams no mundo (SANTOS, et al. 2013). Um dos grandes desafios para as famílias de crianças com a SWB é o diagnóstico, que muitas vezes por despreparo profissional é realizado de forma tardia e equivocado, retardando o acompanhamento direcionado para essa criança, dificultando dessa forma um maior desenvolvimento e suporte para as famílias (SEPULVEDA; RESA, 2021).

Embora seja uma doença com características físicas, clinicas e comportamental marcante, não existe regra para que a criança possua todos esses sinais. Fator esse que pode dificultar o diagnóstico, principalmente quando a equipe multiprofissional que presta assistência não possuir um embasamento satisfatório acerca de todos os aspectos clínicos e genéticos da SWB (MATTOS, et al. 2017).

As características fácies é outro fator determinante para a condução diagnóstica. Vale ressaltar que as características fácies são conhecidas também como "face de gnomo ou fadinha", onde na maioria dos casos são facilmente perceptíveis, quando se possui o conhecimento de suas similaridades. As mais comuns estão descritas no quadro a baixo (Quadro 5).

Quadro 5: Características fácies citadas nos artigos selecionados.

\begin{tabular}{|l|c|}
\hline CARACTERÍSTICAS & $\begin{array}{c}\text { FREQUÊNCIA DE CARACTERÍSTICAS CI- } \\
\text { TADA NOS ARTIGOS SELECIONADOS }\end{array}$ \\
\hline Nariz pequeno e empinado & $30 \%$ \\
\hline Dentes pequenos & $11 \%$ \\
\hline Sorriso largo e frequente & $25 \%$ \\
\hline Estrabismo & $7 \%$ \\
\hline $\begin{array}{l}\text { Aumento do volume da região das } \\
\text { pálpebras }\end{array}$ & $15 \%$ \\
\hline Nariz em cela & $8 \%$ \\
\hline Sulco nasolabial característico & $4 \%$ \\
\hline
\end{tabular}

Fonte: Dados da revisão integrativa, Maceió, AL, 202I. 
Imagem r: Representação da Síndrome de Williams.

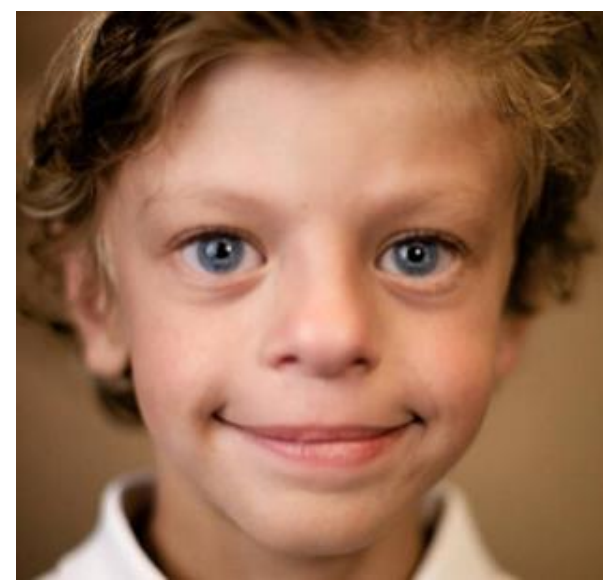

Imagem r: Representação da Síndrome de Williams. Fonte: CASA DE NOTÍCIAS, 2019

A SWB se caracteriza por um conjunto de alterações clínicas que envolvem diversos sistemas do organismo, sendo essas características mais acentuadas em uns, e menos acentuadas em outros. (SOUZA, et al. 2013). A criança pode possuir problemas cardiovasculares, principalmente estenose aórtica supra valvular ou estenose da artéria pulmonar, sendo esse um dos critérios que podem nortear o diagnóstico precoce (SEPULVEDA; RESA, 202I).

Os perfis de personalidade e comportamento da SWB são bem complexos. Geralmente são crianças com personalidade amigável e muito sociável, se apresentando frequentemente com entusiasmo, possuindo sensibilidade com as emoções alheias e preocupação excessiva com determinados assuntos ou objetos (SANTOS, et al. 2013). Já Graziania, et al. (2017); Fernandes, (2014) destaca a irritabilidade, hiperatividade e dificuldade de aprendizado, podendo ser esse um dos fatores que levam a investigação a respeito de síndromes que possam influenciar a fase escolar.

O retardo intrauterino significativo pode influenciar as alterações de crescimento em crianças com a síndrome, apresentando abaixo do normal por I ou $2 \mathrm{~cm} / \mathrm{ano}$, possuindo como característica uma estatura menor nos adultos (SEPULVEDA; RESA, 2021). As alterações endocrinológicas, incluindo problemas de tireoide, alterações osteomusculares, como frouxidão dos ligamentos, que podem atrapalhar no desenvolvimento motor (interferindo na capacidade de sentar, andar e correr) (SOUZA, et al. 2013).

Medeiros, Praxedes, (202I); Pilar, et al. (2018) abordam que a deficiência mental (DM) está presente em todos os casos de SWB, porém, de forma leve a moderada e apresentam dificuldades pontuais como raciocínio espacial, coordenação e equilíbrio, apresentando um atraso psicomotor, no entanto, possui um alto nível de desenvolvimento verbal, solucionar problemas e motricidade fina. Além disso, a criança portadora de SWB possui um atraso no cognitivo e no processo de aprendizagem na escolarização, devido ao déficit global de desenvolvimento que afeta a sua fase de escolaridade. 
Para Souza, et al. (2014), Fernandes (2014), corroboram ao afirmar que esta síndrome apresenta maiores potencialidades em habilidades de linguagem contrastada com o severo déficit em habilidade visual e espacial assim como problemas de atenção, ansiedade nãosocial, fobias e dificuldades com o processamento sensorial. Além do que, a presença de problemas gastrointestinais, como: refluxo gastro esofágico, cólicas, dificuldade em alimentarse, hiperacusia, onde o paciente possui uma sensibilidade maior aos sons, tolerando mal ruídos altos, é muito frequente (FERREIRA, 2018; SEGUIN, et al. 2015).

As características fácies são muito notáveis em crianças com SWB, inclui volume periorbital, íris estrelada em indivíduos com olhos azuis, ponte nasal plana, pequeno nariz arrebitado, filtro longo, perfil facial plano, queixo pequeno e pele delicada, essa aparência facial sofre mudanças, frequentemente com engrossamento dessas características nos adultos (MEDEIROS; PRAXES, 202I; RENGEL et al., 2015). Outras características são os problemas dentários e orais que são comumente encontrados em pacientes com SWB. Achados evidentes incluem dentes pequenos e amplamente afastados, má oclusão e ausência de um ou mais dentes (GONZALES; MARTINS; PELAEZ, 2016). O “prazer pela música é outra característica quase unânime em pacientes com SWB, que inclui habilidades de canto, manuseio de instrumentos musicais e reconhecimento de canções" (PILAR, et al. 2or8; SEPULEDA, RESA 202I).

Quadro 6. Manifestações clinicas descritas na literatura nos artigos selecionados, indexados nas bases de dados LILACS, MEDLINE e SCIELO, no período 2013 a 2021, segundo o ano de publicação. Maceió, 202I.

\begin{tabular}{|c|c|c|}
\hline $\begin{array}{l}\text { AUTORES (ES) } \\
\text { INTEGRADOS }\end{array}$ & $\begin{array}{l}\text { MANIFESTAÇÕES } \\
\text { CLÍNICAS }\end{array}$ & TIPOS \\
\hline $\begin{array}{l}\text { MATOS, et al. 2017; SAL- } \\
\text { VADOR, et al. 2014; SE- } \\
\text { PULVEDA; RESA, 2021; } \\
\text { VIDAL, 2014; MEDEI- } \\
\text { ROS; PRAXEDES, 2021; } \\
\text { FERREIRA, 2014. }\end{array}$ & $\begin{array}{l}\text { Intercorrências do nasci- } \\
\text { mento e da infância. }\end{array}$ & $\begin{array}{l}\text { - Atraso no desenvolvimento } \\
\text { neuropsicomotor; } \\
\text { - Baixo peso ao nascimento; } \\
\text { - Dificuldades no ganho de peso; } \\
\text { - Baixa estatura; } \\
\text { - Hipercalcêmica; } \\
\text { - Otites de repetição; } \\
\text { - Constipação intestinal; } \\
\text { - Hérnia umbilical/ inguinal. }\end{array}$ \\
\hline $\begin{array}{l}\text { MATOS, et al. 2017; SAL- } \\
\text { VADOR, et al. 2014; SE- } \\
\text { PULVEDA; RESA, 2021, } \\
\text { 2021; VIDAL, 2014; ME- } \\
\text { DEIROS; PRAXEDES, }\end{array}$ & $\begin{array}{l}\text { Características } \\
\text { faciais. }\end{array}$ & $\begin{array}{l}\text { - Proeminência supraorbitária; } \\
\text { - Bochechas proeminentes; } \\
\text { - Ponte nasal baixa; }\end{array}$ \\
\hline
\end{tabular}




\begin{tabular}{|c|c|c|}
\hline $\begin{array}{l}\text { 202I; AMARAL, et al; 2014; } \\
\text { FERREIRA, 2014. }\end{array}$ & & $\begin{array}{l}\text { - Narinas antevertidas; } \\
\text { - Filtro nasal longo; } \\
\text { - Macrostomia; } \\
\text { - Anomalias dentárias. }\end{array}$ \\
\hline $\begin{array}{l}\text { MATOS, et al. 2017; SAL- } \\
\text { VADOR, et al. 2014; PE- } \\
\text { REIRA, 2021; MEDEIROS; } \\
\text { PRAXEDES, 2021; FER- } \\
\text { REIRA, 2014. }\end{array}$ & $\begin{array}{c}\text { Características } \\
\text { cardiovasculares. }\end{array}$ & $\begin{array}{l}\text { - Alterações cardíacas (estenose aórtica su- } \\
\text { pravalvar e estenose da artéria pulmonar); } \\
\text { - Hipertensão sistêmica. }\end{array}$ \\
\hline $\begin{array}{l}\text { PEREIRA, 202I; SEPUL- } \\
\text { VEDA; RESA, 202I. }\end{array}$ & $\begin{array}{l}\text { Características } \\
\text { oftalmológicas. }\end{array}$ & $\begin{array}{l}\text { - Estrabismo; } \\
\text { - Íris estrelada. }\end{array}$ \\
\hline $\begin{array}{l}\text { MEDEIROS; PRAXEDES, } \\
\text { 202I; AMARAL, et al; 2014. }\end{array}$ & $\begin{array}{l}\text { Características muscu- } \\
\text { loesqueléticas e renais. }\end{array}$ & $\begin{array}{l}\text { - Clinodactilia do } 5^{\circ} \text { dedo; } \\
\text { - Alterações Renais. }\end{array}$ \\
\hline $\begin{array}{l}\text { MATOS, et al. 2017; SAL- } \\
\text { VADOR, et al. 2014; SE- } \\
\text { PULVEDA; RESA, 2021, } \\
\text { 202I; VIDAL, 2014; ME- } \\
\text { DEIROS; PRAXEDES, } \\
\text { 202I; AMARAL, et al; 2014; } \\
\text { FERREIRA, 2014. }\end{array}$ & $\begin{array}{l}\text { Característica de persona- } \\
\text { lidade, cognição, lingua- } \\
\text { gem e audição. }\end{array}$ & $\begin{array}{l}\text { - Deficiência mental; } \\
\text { - Personalidade amigável; } \\
\text { - Ansiedade; } \\
\text { - Hiperatividade; } \\
\text { - Característica vocal rouca e áspera. }\end{array}$ \\
\hline
\end{tabular}

Fonte: Dados da revisão integrativa, Maceió, AL, 2021.

Anteriormente a síndrome era associada erroneamente a fatores teratogênicos ou apenas maternos, e só foi identificada a partir da década de 9o. A partir dessa época começou a perceber que a região afetada pela síndrome é a do cromossomo 7 , sendo mapeado em 7q11.23, com o gene ELN - elastina, altamente afetado, assim como genes adjacentes (MORADELA; LOPES, 2021; SOUZA, et al. 2014).

A microdeleção do cromossomo 7 envolvida na síndrome ocorre devido a formação genética única nessa região, onde a região cromossômica é flanqueada por conjuntos de genes homólogos e duplicons, que são pseudogenes organizados em blocos de repetição de baixas cópias, que desalinham cada cromossomo 7 durante a meiose podendo levar ao crossing-over desigual e posterior deleção da região da SWB (GRAZIANIA, et al. 2017). Ainda de acordo com o mesmo autor e seus colaboradores a maioria das quebras ocorre em duplicons médios ou centroméricos e leva a uma deleção de aproximadamente I.5 milhões de pares de base de DNA, envolvendo de 26 a 28 genes.

Medeiros; Praxedes, (202I); Ferreira, (2018) corroboram ao afirmar que quanto à etiologia genética da SWB, trata-se de uma síndrome de microdeleção ou de deleção de genes 
contíguos, causada pela perda de uma cópia de aproximadamente 2i genes presentes na região 7qII-23, que abrange 1.5 a 1.8 milhões de pares de bases. Sendo assim na maioria dos casos, a deleção ocorre esporadicamente, porém, há relatos de famílias com herança autossômica dominante para essa síndrome.

Apesar de "2I genes terem sido identificados na deleção da SWB, suas contribuições individuais para os fenótipos dos pacientes ainda não estão completamente estabelecidas" (SOUZA, et al. 2014). A deleção do gene da elastina (ELN) é a que está bem delimitada, interferindo na elasticidade de órgãos alvo, a hemizigosidade do ELN é necessária, não sendo suficiente para causar, sozinha, a Síndrome de Williams-Beuren (MARTINS, et al. 2014; SANTOS, et al. 2013).

Ferreira, (2018) afirma que a "maioria dos adultos com SWB escolhem não reproduzir, mas aqueles que reproduzem têm uma chance de $50 \%$ que cada filho herde a síndrome." O risco maior ocorre devido a um aumento nos eventos de desalinhamento dos cromossomos 7 durante a meiose.

Já Medeiros, Praxedes, (202I) expõem que portadores de inversão da região crítica da SWB são mais propensos a produzir um gameta que abriga a região cromossômica da SWB deletada, tendo um risco 4 vezes maior de transmitir a deleção à prole.

Devido ao déficit de conhecimento acerca da SWB o diagnóstico ocorre muitas vezes de forma tardia, principalmente nos casos em que o paciente não nasce com uma cardiopatia expressiva que muitas vezes norteiam o diagnóstico. Portanto Souza, et al. (2014); Ferreira, (2018); Mattos, et al. (2017), enfatizam que a suspeita diagnóstica é baseada na evolução e história clínica durante os primeiros anos de vida, quando os sinais se tornam mais evidentes e as confirmações genéticas.

A identificação do tamanho das deleções dos pacientes com SWB e quais genes estão envolvidos em cada deleção pode fornecer informações valiosas para a correlação genótipo-fenótipo e essas informações podem ser obtidas através da aplicação das técnicas citomoleculares (SOUZA, et al. 2013). Atualmente as técnicas citomoleculares que são mais utilizadas no diagnóstico laboratorial são as de hibridação in situ por fluorescência (FISH), a de multiplicação de múltiplas sondas dependentes de ligação (MLPA) e a hibridização genômica comparada por arrays $(\mathrm{aCGH})$, entretanto, são aplicadas duas para confirmar o diagnóstico clínico da SWB, apresentando graus de detecções e informações diferentes (FERREIRA, 2018).

Segundo os autores aqui pesquisados, o diagnóstico precoce norteia tanto o paciente como o tratamento necessário para cada caso, fornecendo maior independência e autonomia dessa criança. Logo, dessa forma pode auxiliar desde a infância a interagir da melhor forma com o meio social, traçando estratégias para a sua inserção no meio escolar, como o manejo da sua independência na vida adulta (MEDEIROS, PRAXEDES, 202I).

Faz-se necessário que os profissionais de saúde possuam um conhecimento satisfatório sobre os sinais clínicos e genéticos da doença. A grande variação no fenótipo da síndrome, em muitos casos, acaba dificultando e atrasando o diagnóstico clínico. Tendo isso em vista é necessário que os profissionais da saúde possuam um conhecimento amplo relacionado a essa patologia, conhecimento este, que englobem além dos conhecimentos fenotípicos e aspectos clínicos, respaldo para direcionar o diagnóstico laboratorial.

No estudo de Amaral, et al. (2013); Bezerra (2016), foi perceptível que os pais traçam uma luta diária até o fechamento do diagnostico, sufocados por incertezas e sem norte na 
condução da qualidade de vida do seu filho. Consequentemente, nota-se que é de grande relevância que as crianças acometidas pela síndrome, sejam bem assistidas e acompanhadas por uma equipe multidisciplinar de profissionais da saúde e de educação que assistam essa criança de forma holística, devido aos sinais e sintomas inerentes a sua condição, bem como, possíveis complicações as quais possam surgir no decorrer das suas vidas (FERNANDES. 2014; MARTINS, et al. 2016).

Como na maioria das doenças genéticas, a SWB não possui ainda um método capaz de corrigir a perda de material genético, restabelecendo o perfeito funcionamento do organismo. Porém existem tratamentos atenuantes e acompanhamento de crucial relevância, as consequências da SWB. Esses acompanhamentos podem ocasionar a criança uma melhor qualidade de vida, relacionada aquelas que não seguem acompanhamento na medida correta, onde o intuito dessas medidas é buscar atenuar os sintomas, tratar as condições associadas e, sobretudo, prevenir complicações. Entre as medidas imprescindíveis ao tratamento citadas ao longo desta pesquisa, algumas possuíam semelhanças entre os autores, onde podem ser destacadas na tabela abaixo.

Quadro 7. Tratamento sugerido e sua justificativa. Maceió, 202I.

\begin{tabular}{|c|c|c|}
\hline TRATAMENTO SUGERIDO & JUSTIFICATIVA & $\%$ \\
\hline Acompanhamento médico regular. & $\begin{array}{l}\text { Esse profissional pode identificar e nortear o pa- } \\
\text { ciente no enfrentamento da doença. }\end{array}$ & $22 \%$ \\
\hline $\begin{array}{l}\text { Acompanhamento com equipe multiprofissio- } \\
\text { nal. }\end{array}$ & $\begin{array}{l}\text { Por se tratar de uma síndrome global, que afeta } \\
\text { diversos seguimentos da criança, se faz necessá- } \\
\text { rio um acompanhamento holístico, com uma e- } \\
\text { quipe que vise o todo do paciente e somem forças } \\
\text { para a melhora, para o diagnóstico precoce e qua- } \\
\text { lidade de vida. }\end{array}$ & $18 \%$ \\
\hline $\begin{array}{l}\text { Monitoração da pressão arterial e frequência } \\
\text { cardíaca. }\end{array}$ & Devido ao estreitamento das artérias. & $14 \%$ \\
\hline Atenção à função renal e intestinal. & Decorrente ao excesso de cálcio na circulação. & $8 \%$ \\
\hline $\begin{array}{c}\text { Frequentes avaliações oftalmológicas, odonto- } \\
\text { lógicas, ortopédicas e auditivas. }\end{array}$ & $\begin{array}{l}\text { O paciente de Williams pode ter o comprometi- } \\
\text { mento das funções desses sistemas. }\end{array}$ & $10 \%$ \\
\hline $\begin{array}{l}\text { Acompanhamento rigoroso da curva de cresci- } \\
\text { mento e do ganho de peso. }\end{array}$ & $\begin{array}{l}\text { Devido ao fato que } 29 \% \text { dessa população apre- } \\
\text { senta obesidade na vida adulta. }\end{array}$ & $12 \%$ \\
\hline Programas especiais de educação. & $\begin{array}{l}\text { Favorecem o desenvolvimento da aprendizagem } \\
\text { e a integração do portador da doença na socie- } \\
\text { dade. }\end{array}$ & $16 \%$ \\
\hline
\end{tabular}

Fonte: Dados da revisão integrativa, Maceió, AL, 202I.

O enfermeiro como um profissional que presta assistência humanizada a criança em seu crescimento e desenvolvimento desde o nascimento, pode identificar possíveis alterações na saúde da criança, norteando os pais para a busca de diagnóstico precoce (NONATO et al. 2020; GUENAT, 2016; NANDA, 2018).

A "assistência à saúde da criança é uma atividade de fundamental importância em função da vulnerabilidade nessa fase do ciclo de vida, onde o acompanhamento da criança na puericultura espera-se reduzir a incidência de doenças" (SILVA et al., 2017; CREPALDI, 2018). 
De acordo com Coelho, et al. (2016) é necessário a detecção e intervenção precoce de possíveis atrasos nos três primeiros anos de vida, sendo a triagem nas consultas de rotina algo indispensável a criança apresentando fatores de riscos, ou não, para patologias. $\mathrm{O}$ enfermeiro pode utilizar como base para consultas de puericultura, o programa de Atenção Integrada a Doenças Prevalentes na Infância (AIDPI), além da ampliação do conhecimento para patologias menos frequentes como a Síndrome de Williams-Beuren (CORREA, MINETTO e CREPALDI, 2018).

Dessa forma, se faz necessário o conhecimento aprofundado acerca da Síndrome de Willians-Beuren, sabendo que o diagnóstico precoce, e a condução holística da patologia são de crucial importância, onde o enfermeiro possui como proposito às ações assistenciais, contribuindo de maneira especifica a integralidade do cuidado (MATTOS, et al. 2017; COELHO, et al. 2016).

Visto que os fatores de risco para o atraso de crianças diagnosticadas com SWB são múltiplos, e o acúmulo de condições podem determinar maiores impactos no desenvolvimento da criança, instruir as famílias de crianças com SWB é essencial (DORNELAS e MAGALHAES 20I6; SILVA et al. 2017). É importante para famílias com crianças que tenham o diagnóstico de SWB, estabelecer uma rede de apoio, de atenção e proteção ao desenvolvimento da criança, buscando identificar os fatores de risco, compreender a criança, a sua família e o próprio contexto em que estão inseridos para uma melhor assistência.

Como "resultado do aprofundamento das características peculiares da síndrome, e apreensão da necessidade de um cuidado sistematizado e individualizado pelo enfermeiro e equipe interdisciplinar" (NONATO, et al 2020), se percebe a necessidade do enfermeiro elaborar um Plano de Cuidados, a partir de Diagnósticos de Enfermagem com base na Taxonomia NANDA 2018- 2020 (NANDA, 2018), contemplando as etapas de hipóteses, de solução e aplicação à realidade, visando nortear a melhor condução para as possibilidades ocasionadas por tal patologia.

Quadro 8. Plano de Cuidados à criança com Síndrome de Williams-Beuren.

\begin{tabular}{|l|l|l|l|}
\hline \multicolumn{1}{|c|}{ Classe } & \multicolumn{1}{|c|}{ Diagnóstico } & Fator relacionado ao risco & \multicolumn{1}{c|}{ Prescrição de Enfermagem } \\
\hline $\begin{array}{l}\text { Função Respira- } \\
\text { tória }\end{array}$ & $\begin{array}{l}\text { Respiração prejudi- } \\
\text { cada }\end{array}$ & $\begin{array}{l}\text { Presença de estenose aórtica } \\
\text { supravalvar. }\end{array}$ & $\begin{array}{l}\text { - Manter a criança em posições que } \\
\text { favoreçam a expansão torácica, como } \\
\text { Fowler ou Semi Fowler. }\end{array}$ \\
\hline $\begin{array}{l}\text { Hidratação di- } \\
\text { minuída. }\end{array}$ & $\begin{array}{l}\text { Risco de desequilí- } \\
\text { brio eletrolítico. }\end{array}$ & Disfunção renal. & $\begin{array}{l}\text {-Orientar a criança a reconhecer sua } \\
\text { necessidade de momentos de repouso. }\end{array}$ \\
\hline $\begin{array}{l}\text { Lesão perifé- } \\
\text { rica. }\end{array}$ & $\begin{array}{l}\text { Risco de disfunção } \\
\text { neurovascular perifé- } \\
\text { rica. }\end{array}$ & $\begin{array}{l}\text { Obstrução vascular. } \\
\text { com menor concentração de sais mi- } \\
\text { nerais. }\end{array}$ & $\begin{array}{l}\text { - Manter extremidades aquecidas. } \\
\text { - Hidratação constante. }\end{array}$ \\
\hline $\begin{array}{l}\text { Desenvolvi- } \\
\text { mento na a- } \\
\text { prendizagem. }\end{array}$ & $\begin{array}{l}\text { Risco de desenvolvi- } \\
\text { mento atrasado. }\end{array}$ & $\begin{array}{l}\text { Relacionado ao distúrbio ge- } \\
\text { nético. }\end{array}$ & $\begin{array}{l}\text { - Aplicar a curva de neurodesenvolvi- } \\
\text { mento, considerando a presença da } \\
\text { síndrome. }\end{array}$ \\
\hline
\end{tabular}




\begin{tabular}{|l|l|l|l|}
\hline & & & $\begin{array}{l}\text { - Associar o cuidado de saúde ao âm- } \\
\text { bito escolar, formulando parceria com } \\
\text { o centro de educação para acompa- } \\
\text { nhar o desenvolvimento neurológico } \\
\text { quanto ao aprendizado. }\end{array}$ \\
\hline $\begin{array}{l}\text { Agitação pre- } \\
\text { sente. }\end{array}$ & $\begin{array}{l}\text {-Conforto prejudi- } \\
\text { cado. } \\
\text {-Estresse Presente. }\end{array}$ & $\begin{array}{l}\text { Sintomas da doença. } \\
\text { - Estabelecer rotina de relaxamento } \\
\text { com terapias complementares como } \\
\text { musicoterapia; cromoterapia, ludote- } \\
\text { rapia, florais, ervas, banhos termais } \\
\text { entre outros. }\end{array}$ \\
\hline
\end{tabular}

Fonte: Dados da revisão integrativa, Maceió, AL, 2021.

\section{CONSIDERAÇÕES FINAIS}

Diante do exposto pode-se perceber que as pesquisas sobre a Síndrome de WilliamsBeuren ainda ocorrem de forma limitada, sendo algo perceptível pelos autores, na busca de fundamentação teórica para tal pesquisa. Além da escassez de artigos publicados nacionais sobre a SWB, a pouca quantidade que foi encontrada era com mais de dez anos de publicação. Com isso vale ressaltar desde já, a estrema necessidade de possuir mais pesquisas sobre a temática, visto as relevâncias do conhecimento amplo sobre tal, demonstrada ao longo dessa pesquisa.

Algo bem enfatizado foi a crucial importância do diagnóstico precoce, para que as intervenções e acompanhamentos sejam efetuados de forma direcionada, contribuindo dessa forma para uma melhor qualidade de vida, tanto da criança quanto para a família, que muitas vezes vive no dilema sofrido para encontrar a conclusão diagnóstica.

Tendo isso em vista, é de extrema importância que os profissionais de saúde possuam um conhecimento satisfatório sobre tal patologia. Visto que a assistência ocorre de forma integral e de forma multidisciplinar norteando os aspectos mínimos característicos na busca diagnóstica.

O enfermeiro como está à frente em todos os níveis de atenção à saúde, representa um papel preponderante na assistência diária de diversas patologias, devendo o mesmo estar inteirado sobre a SWB para nortear as famílias e prestar uma assistência holística a este paciente.

Dessa forma se faz relevante o conhecimento sobre tal doença desde a formação acadêmica desse profissional, para que se desperte o interesse de pesquisar e traçar estratégias para contribuir com a qualidade de vida do mesmo.

\section{REFERÊNCIAS}

ALMEIDA K. M., FONSECA S. T., FIGUEIREDO P. R.P., AQUINO A. A., MANCINI M. C. Effects of interventions with therapeutic suits (clothing) on impairments and functional limitations of children with cerebral palsy: a systematic review. Brazilian Journal of Physical Therapy, Volume 21; 307-320, 2017.

AMARAL, et al. Estresse em crianças e adolescentes com Síndrome de Williams-Beuren em idade escolar. Revista Semestral da Associação Brasileira de Psicologia Escolar e Educacional, SP. V. I7, n.I, p.I05-II2, janeiro / junho de 2014. 
CASA DE NOTÍCIAS. Conhece a síndrome de Williams? 2019. Disponível em: https://www.casadenoticias.com.br/noticias/29942-conhece-a-sindrome-de-williams. Acesso em: 27 julho de 202I.

COELHO, R; et al. Child development in primary care: a surveillance Proposal. Jornal de Pediatria, Porto Alegre, v.92, n.5, p.505-511, oct. 2016.

CORREA, W; MINETTO, M. F; CREPALDI, M. A. Família como promotora do desenvolvimento de crianças que apresentam atrasos. Pensando famílias, Porto Alegre, v.22, n.I, p.44-58, jun. 2018.

DORNELAS, L. F; MAGALHAES, L. C. Functional performance of school children diagnosed with developmental delay up to two years of age. Revista Paulista de Pediatria, São Paulo, v.34, n.I, p.78-85, mar. 2016.

FERREIRA, K. R. A aquisição da linguagem por parte de crianças com Síndrome de Williams: Um estudo de caso sobre a compreensão de sentenças passivas. Teoria gerativa: perspectivas e desafios. n.33, 2018.

GRAZIANIA, L. M; JACKOWSKIA, A. P; ROSSITB, R. A. S; COLEA, C. G. D. Avaliação da influência dos sintomas clínicos na qualidade de vida de indivíduos com Síndrome de Williams-Beuren. Cad. Ter. Ocup. UFSCar, São Carlos, v. 25, n. I, p. p. 125-135, 2017.

GUENAT, David; et al. DNA damage response defect in Williams-Beuren syndrome. International Journal of Molecular Medicine, n.39, v.3, p.622-628, 2017.

HONJO, R.S. et al. Deletion in Williams-Beuren syndrome critical region detected by MLPA in a patient with supravalvular aortic stenosis and learning difficulty. J. Genet. Genomics, v. 39, p. 571-574, 2013.

LIMA, I; CARVALHO, S. G. Produção e avaliação de video documental como recurso de orientação para pais e cuidadores de crianças e adolescentes com Síndrome de WilliamsBeuren. Sitema de publicação eletrônica de desses e dissertações. V. 22, n. 6, 2015.

LIMA, S. F. B; TEIXEIRA, M. C. T. V; SEGIN, M; CARREIRO, L. R. R. Recomendações psicopedagógicas para o trabalho da equipe educacional com escolares com síndrome de Williams. Psicopedagogia ; v.29, n. 88, p. 74-76, 2012.

MATTOS, G. L. M; PAROLIN, J. A. P; ROSSIT, SALVADOR, R. A; COLE, D; GREGO, C. Avaliação da influência dos sintomas clínicos na qualidade de vida de indivíduos com Síndrome de Williams-Beuren. Cad. Ter. Ocup. UFSCar ; v.25, n.I, p.125-135, 2017. 
MEDEIROS, A. B. D; PRAXEDES, L. A. Correlações entre o fenótipo na síndrome de Williams e os genes deletados. Brazilian Journal of Health Review, Curitiba, v.4, n.I, p.2128-2141, 2021.

NANDA INTERNATIONAL. Diagnósticos de enfermagem da NANDA-I: definições e classificação 2018-2020. II.ed. Porto Alegre: Artmed, 2018

NONATO, A. M. et al. CUIDADO DE ENFERMAGEM NA ATENÇÃO PRIMÁRIA À CRIANÇA COM SÍNDROME DE WILLIAMS-BEUREN: UMA REVISÃO INTEGRATIVA. Revista Destaques Acadêmicos, Lajeado, v. I2, n. 3, 2020.

ROSSI, N. F., FERREIRA, M. D., GIACHETI, M. C. Genética e linguagem na síndrome de Williams-Beuren: uma condição neuro-cognitiva peculiar. Pró-Fono Revista de atualização Científica, vol.18, n.3, Barueri Sept. / Dec. 2006.

SANTOS, A. V. A. A; MOREIRA, N. M; SAYURI, H. R; LELIS, D. R; BAPTISTA, A. F; KIM, CHONG, A. Estresse em crianças e adolescentes com Síndrome de WilliamsBeuren em idade escolar. Psicol. esc. educ ; v.17, n.I, p.I05-112, jun. 2013.

SEMBERG, C., SCHROTER, C. G., ABOITIZ, D. Síndrome de Williams: estúdio clínico citogenético, neurofisiológico e neuroanatômico. Revista Médica de Chile, vol.rzo, n. 6, p. 631-637, Santiago. Jun 2002.

SEPÚlVEDA, M. E; RESA, L. P. Avaliação da qualidade de vida em famílias com pacientes com Síndrome de Williams. Health Qual Life Outcomes ; v.I9, n.I, p.I2I, 202I.

SILVA, E. B, et al. Mapping of nursing activities related to diagnosis: delayed growth and development. Revista Rene, Fortaleza, v.18, n.2, p.234-24I, abr. 2017.

SOUZA, S. L; NEVES, J. A. F; ANNELISE, J. C; SANTOS, C. M. R; GERALDI, H. $\mathrm{V}$. Investigação dos domínios cognitivos de pacientes com síndrome de williams usando as escalas wechsler. Psicol. pesq; v.7, n.2, p. 200-207, dez. 2014.

VIDAL, N. M; CAROLINO, W. M; CAVALCANTE, I. S; CARVALHO, M. D. F. Síndrome de Williams-Beuren: uma revisão da literatura. Revista Bioeducação. v.48, n.ıo, out. 2014 . 